Original article

\title{
Baseline results from the European non-interventional Antipsychotic Long acTing injection in schizOphrenia (ALTO) study
}

\author{
Pierre-Michel Llorca ${ }^{\mathrm{a}}$, Julio Bobes ${ }^{\mathrm{b}}$, W. Wolfgang Fleischhacker ${ }^{\mathrm{c}}$, Stephan Heres ${ }^{\mathrm{d}}$, \\ Nicholas Moore ${ }^{\mathrm{e}}$, Nawal Bent-Ennakhil ${ }^{\mathrm{f}}$, Christophe Sapin ${ }^{\mathrm{f}}$, Jean-Yves Loze ${ }^{\mathrm{g}}$, \\ Anna-Greta Nylander ${ }^{\mathrm{h}, *}$, Maxine X. Patel ${ }^{\mathrm{i}}$ \\ a University Hospital Center, EA 7280 University Clermont Auvergne, Clermont-Ferrand, France \\ ${ }^{\mathrm{b}}$ Department of Psychiatry - CIBERSAM, University of Oviedo, Oviedo, Spain \\ ${ }^{\mathrm{c}}$ Department of Psychiatry, Psychotherapy and Psychosomatics, Division of Psychiatry, Medical University Innsbruck, Innsbruck, Austria \\ d Department of Psychiatry and Psychotherapy, Munich Technical University, Munich, Germany \\ e Department of Pharmacology, University of Bordeaux, Bordeaux, France \\ ${ }^{\mathrm{f}}$ Lundbeck SAS, Issy-les-Moulineaux, France \\ g Otsuka Pharmaceutical Europe Ltd., Wexham, United Kingdom \\ ${ }^{\mathrm{h}}$ H. Lundbeck A/S, Ottiliavej 9, Valby, 2500, Denmark \\ i Department of Psychosis Studies, Institute of Psychiatry, Psychology and Neuroscience, King's College London, London, United Kingdom
}

\section{A R T I C L E I N F O}

Article history:

Received 5 January 2018

Received in revised form 6 April 2018

Accepted 7 April 2018

Available online 4 May 2018

\section{Keywords:}

Antipsychotic agents

Schizophrenia

Long-acting injectable

Medication adherence

Prescriptions

\section{A B S T R A C T}

Background: The Antipsychotic Long-acTing injection in schizOphrenia (ALTO) study was a noninterventional study across several European countries examining prescription of long-acting injectable (LAI) antipsychotics to identify sociodemographic and clinical characteristics of patients receiving and physicians prescribing LAIs. ALTO was also the first large-scale study in Europe to report on the use of both first- or second-generation antipsychotic (FGA- or SGA-) LAIs.

Methods: Patients with schizophrenia receiving a FGA- or SGA-LAI were enrolled between June 2013 and July 2014 and categorized as incident or prevalent users. Assessments included measures of disease severity, functioning, insight, well-being, attitudes towards antipsychotics, and quality of life.

Results: For the 572 patients, disease severity was generally mild-to-moderate and the majority were unemployed and/or socially withdrawn. 331/572 were prevalent LAI antipsychotic users; of whom 209 were prescribed FGA-LAI. Paliperidone was the most commonly prescribed SGA-LAI (56\% of incident users, $21 \%$ of prevalent users). 337/572 (58.9\%) were considered at risk of non-adherence. Prevalent LAI users had a tendency towards better insight levels (PANSS G12 item). Incident FGA-LAI users had more severe disease, poorer global functioning, lower quality of life, higher rates of non-adherence, and were more likely to have physician-reported lack of insight.

Conclusions: These results indicate a lower pattern of FGA-LAI usage, reserved by prescribers for seemingly more difficult-to-treat patients and those least likely to adhere to oral medication.

Crown Copyright (c) 2018 Published by Elsevier Masson SAS. This is an open access article under the CC BY license (http://creativecommons.org/licenses/by/4.0/).

\section{Introduction}

Schizophrenia, typically a chronic mental illness with a high risk of relapse, impairs cognitive and social functioning and can negatively impact on health and quality of life [1-3]. Relapse in people with schizophrenia may lead to hospitalization, reduced social and work-based functioning, increased stigma and higher risk

\footnotetext{
* Corresponding author.

E-mail address: AGN@lundbeck.com (A.-G. Nylander).
}

of suicide or homicide [4,5]. Antipsychotics are used for relapse prevention, however non-adherence is a significant barrier [6,7].

Multiple factors can contribute to non-adherence [8] and it is not only difficult to predict, but also difficult to identify and measure [9]. Long-acting injectable (LAI) antipsychotics were developed to improve adherence and reduce the likelihood of treatment cessation [10-12]. A meta-analysis of 16 naturalistic mirror-image studies in patients with schizophrenia found LAI antipsychotics were associated with a significant reduction in hospitalization, or risk of hospitalization than oral antipsychotics [13]. Other registry-based naturalistic studies have shown that in clinical practice, LAIs reduce hospitalizations more effectively than 
oral antipsychotics [14-16]. However, a meta-analysis of randomized controlled trials showed no benefit of LAIs over oral formulations [17]. Differences in methodology between study types may explain these variable results [17,18]. Despite the potential for LAIs to impact positively on adherence and clinical outcomes, prescription rates vary considerably between service providers [19], and often fall below $20 \%$ nationally [7].

Appropriate prescribing of LAI antipsychotics is affected by several factors including variable pharmacokinetics [20], delayed resolution of side-effects [7], patient fear of injection, and negative patient and physician attitudes towards LAIs [7,21]. Consequently, LAI antipsychotics are often potentially reserved for patients with a history of relapse and poor compliance to oral medication [7,21-24].

The primary aim of the Antipsychotic Long-acTing injection in schizOphrenia (ALTO) study was to describe utilization of firstand second-generation (FGA- and SGA-) LAI antipsychotic treatments, and the sociodemographic and clinical characteristics of patients with schizophrenia from different countries in Europe, as well as the characteristics of their prescribing physicians. The secondary aim was to identify subgroups of LAI antipsychotic patients with common attributes to ascertain whether the sociodemographic and clinical characteristics of patients receiving FGA- or SGA-LAIs differed.

\section{Experimental procedures}

\subsection{Study design}

ALTO was a multi-site, non-interventional study across several European countries investigating LAI antipsychotics usage in inpatients and outpatients with schizophrenia, and included the assessment of patient functioning and insight as recommended by the US Food and Drug Administration and European Medicines Agency [25-27].

ALTO study design is shown in Fig. 1A. The baseline population encompassed 4 LAI user types: FGA- and SGA-LAI incident users and FGA- and SGA-LAI prevalent users. Incident users were defined as patients who started LAI treatment at study baseline ( \pm 14 days) with

A

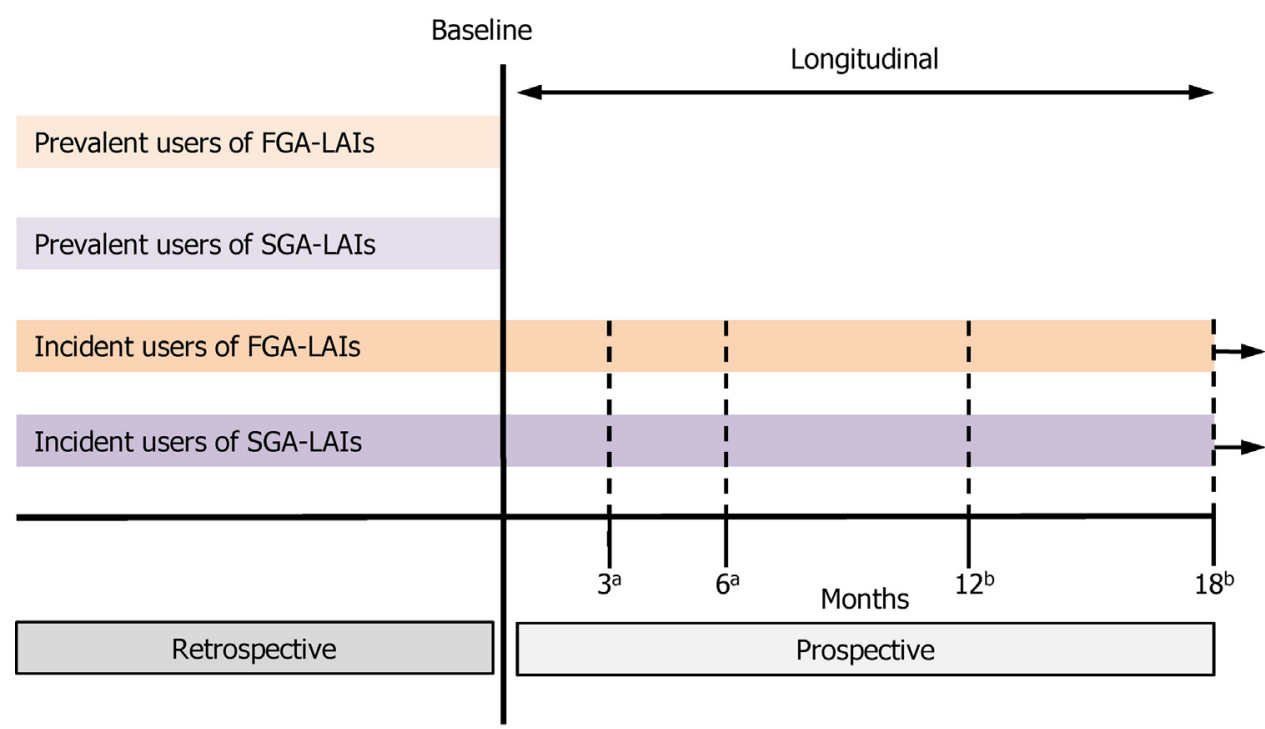

B

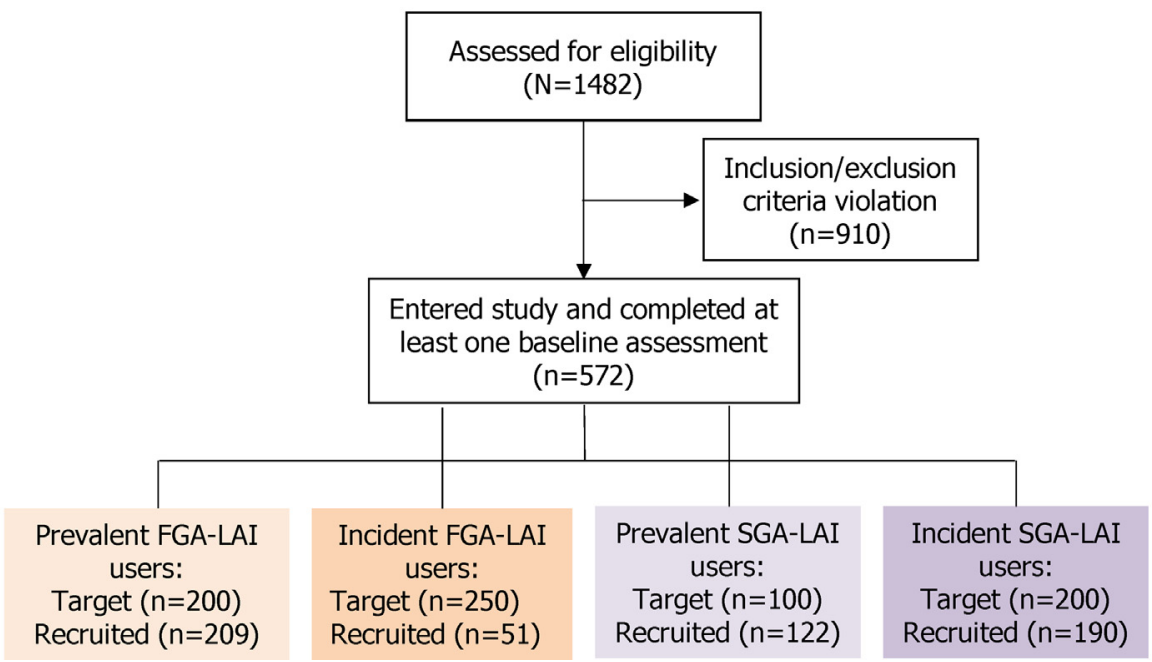

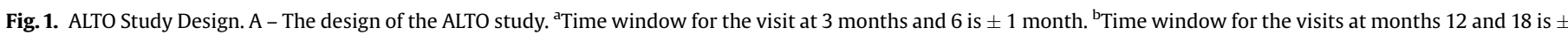

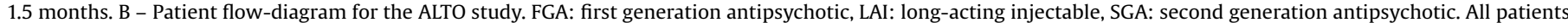

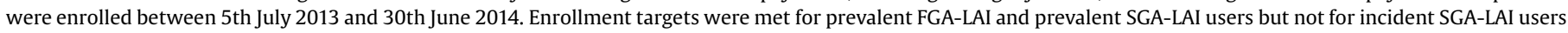
(95\% of the target attained) or for incident FGA-LAI users ( $20 \%$ of the target attained). 
a LAI antipsychotic that was not prescribed during the previous 12 months; all other patients were considered prevalent users. All investigators were advised to prescribe in accordance with recommendations in the local summary of product characteristics for the chosen drug. Choice of LAI antipsychotic was independent of the study protocol and the decision to include the patient in the study. Local ethics committee approvals were obtained for the study.

\subsection{Sample}

Sample size estimation was based on 95\% confidence interval (CI) of the Subjective Well-being under Neuroleptic Scale - short form (SWN-S) total score at study endpoint. Previous reports [2834] suggest a change from baseline SWN-S between 4 and 8 points is considered clinically meaningful, with standard deviations (SDs) from 12 to 18 [28-34]. Assuming a SD of 18 in the SWN-S score, 312 patients provided a 2 -sided $95 \% \mathrm{CI}$ of the score with a width of 4 points. Considering a global attrition rate of $30 \%$, 450 incident users were targeted for enrollment. It was estimated that 300 prevalent users should be recruited alongside this, giving a total planned cohort of 750 patients. Estimated numbers of patients falling into the FGA- and SGA-LAI categories were calculated for incident and prevalent users.

Patients were enrolled in Austria, France, Germany, Spain, Sweden, and the United Kingdom (UK) from hospitals, mental health centers, private settings, specialized units for LAI antipsychotic administration, and primary care settings involved in managing inpatients and/or outpatients treated with LAI antipsychotics.

Recruitment was by naturalistic enrollment of patients who agreed to participate and met the inclusion criteria. The dates of first and last patient visits were July 2013 and June 2014, respectively. Recruitment targets were 250 and 200 for incident and prevalent users of FGA-LAIs, and 200 and 100 for incident and prevalent users of SGA-LAIs, respectively. It was intended that each site should not recruit $>10 \%$ of the target for France, Germany, Spain or the UK ( $>20 \%$ for Austria and Sweden).

Inclusion criteria included inpatient/outpatient status, aged $\geq 18$ years, a diagnosis of schizophrenia (by International
Classification of Disease-10 criteria), and receipt of FGA- or SGALAI. Exclusion criteria included being pregnant or breastfeeding, having acute serious or unstable medical conditions (other than schizophrenia), and having attempted suicide in the past 30 days. Signed informed consent was required before study enrollment.

\subsection{Study assessments}

A range of physician and patient assessment tools were utilized (Table 1).

\subsubsection{Physician, patient, and site characteristics}

Physician's site, physician characteristics, and physician-estimated risk of non-adherence were recorded. At baseline, patient profiles included sociodemographics (age, gender, education, and profession), patient autonomy (including living autonomy: with family, alone, with friend(s) or homeless), and eating autonomy (able to manage own meal, eats meals regularly with caregiver/family support, unable to have regular meals). Caregiver status (support of a nurse/relative/others or absence of caregiver), evidence of social withdrawal, disease history, relapses within the previous year, comorbidities, and treatment-resistant status (previous use of clozapine) were recorded. Patient clinical characteristics included medical and psychiatric history, autonomy and caregiver status, previous and current antipsychotic medication, concomitant medication, and treatment pattern including prior treatment.

\subsubsection{Side effects}

All adverse drug reactions observed by the investigator or spontaneously reported by the patient were recorded, and rated (incident users only) using the Udvalg for Kliniske Undersøgelser (UKU) side effect rating scale [35].

\subsubsection{Patient- and physician-reported clinical assessments}

Clinician assessment of severity of the patient's current mental illness was rated on the Clinical Global Impression-Severity (CGI-S) scale [36,37], with remission defined as $\leq 2$ ('Normal, not at all ill' or 'Borderline ill'). Physician-assessed measurements of patients'

Table 1

Study Assessments.

\begin{tabular}{|c|c|c|c|c|c|c|c|}
\hline \multicolumn{8}{|l|}{ Baseline Only Assessments } \\
\hline Relevance & \multicolumn{7}{|l|}{ Assessment } \\
\hline Physician Data & \multicolumn{7}{|l|}{ Physician profile } \\
\hline Physician Attitudes & \multicolumn{7}{|l|}{ Physician attitude towards long-acting injectables (LAIs) questionnaire } \\
\hline Patient Data & \multicolumn{7}{|l|}{ Medical and psychiatric history } \\
\hline Adherence & \multicolumn{7}{|l|}{ Non-adherence risk } \\
\hline \multicolumn{8}{|l|}{ Longitudinal Assessments } \\
\hline \multirow[t]{2}{*}{ Relevance } & \multirow[t]{2}{*}{ Assessment } & \multirow[t]{2}{*}{ Baseline } & \multicolumn{4}{|c|}{ Time (months) } & \multirow[t]{2}{*}{ Withdrawal } \\
\hline & & & 3 & 6 & 12 & 18 & \\
\hline \multirow[t]{2}{*}{ Patient Data } & Sociodemographics & $\mathrm{X}$ & $\mathrm{X}$ & $\mathrm{X}$ & $\mathrm{X}$ & $\mathrm{X}$ & $\mathrm{X}$ \\
\hline & Autonomy and caregiver status & $\mathrm{X}$ & $\mathrm{X}$ & $\mathrm{X}$ & $\mathrm{X}$ & $\mathrm{X}$ & $\mathrm{X}$ \\
\hline Adverse Events & Adverse Drug Reaction assessment ${ }^{\mathrm{a}}$ & $\mathrm{X}^{\mathrm{b}}$ & $\mathrm{X}$ & $\mathrm{X}$ & $\mathrm{X}$ & $\mathrm{X}$ & $\mathrm{X}$ \\
\hline \multirow[t]{2}{*}{ Health Economic Relevance } & Previous and current antipsychotic medication, concomitant medication, treatment pattern ${ }^{a}$ & $\mathrm{X}$ & $\mathrm{X}$ & $\mathrm{X}$ & $\mathrm{X}$ & $\mathrm{X}$ & $\mathrm{X}$ \\
\hline & Resource use & $\mathrm{X}$ & $\mathrm{X}$ & $\mathrm{X}$ & $\mathrm{X}$ & $\mathrm{X}$ & $\mathrm{X}$ \\
\hline Health Status & Clinical Global Impression-Severity (CGI-S) & $\mathrm{X}$ & $\mathrm{X}$ & $\mathrm{X}$ & $\mathrm{X}$ & $\mathrm{X}$ & $\mathrm{X}$ \\
\hline \multirow[t]{2}{*}{ Functioning } & Personal and Social Performance (PSP) & $\mathrm{X}$ & $\mathrm{X}$ & $\mathrm{X}$ & $\mathrm{X}$ & $\mathrm{X}$ & $\mathrm{X}$ \\
\hline & Global Assessment of Functioning (GAF) & $\mathrm{X}$ & $\mathrm{X}$ & $\mathrm{X}$ & $\mathrm{X}$ & $\mathrm{X}$ & $\mathrm{X}$ \\
\hline \multirow[t]{2}{*}{ Insight } & Positive and Negative Syndrome Scale, Item G12 (PANSS G12) & $\mathrm{X}$ & & & & $\mathrm{X}$ & $\mathrm{X}$ \\
\hline & Insight Scale (IS) & $\mathrm{X}$ & & & & $\mathrm{X}$ & $\mathrm{X}$ \\
\hline \multirow[t]{2}{*}{ Quality of Life } & Subjective Well-Being under Neuroleptic Scale, short form (SWN-S) & $\mathrm{X}$ & $\mathrm{X}$ & $\mathrm{X}$ & $\mathrm{X}$ & $\mathrm{X}$ & $\mathrm{X}$ \\
\hline & Tolerability and Quality of Life (TooL) & $\mathrm{X}$ & & $\mathrm{X}$ & $\mathrm{X}$ & $\mathrm{X}$ & $\mathrm{X}$ \\
\hline Patient Attitudes & Drug Attitude Inventory - short version (DAI-10) & $\mathrm{X}$ & $\mathrm{X}$ & $\mathrm{X}$ & $\mathrm{X}$ & $\mathrm{X}$ & $\mathrm{X}$ \\
\hline
\end{tabular}

Patient-reported outcomes included the IS, SWN-S, TooL and DAI-10. Physician-reported outcomes included the CGI-S, PSP, GAF and PANSS G12.

a Also assessed at change of treatment.

b Not reported in the baseline report. 
level of functioning included Personal and Social Performance (PSP) and Global Assessment of Functioning (GAF) [38]. Item G12 from the PANSS (Positive and Negative Symptom Scale) was selected for physicians to rate patients' lack of insight [39]. The Insight Scale (IS) was included to complement the PANSS G12 as a more comprehensive measurement of patient insight and treatment acceptability [40]. The $S W N-S$ was provided for patients to score their own well-being on antipsychotic treatment [41]. The Tolerability and quality of Life (TooL) was used to assess the impact of side effects on quality of life from the patient perspective [42]. The Drug Attitude Inventory - short version (DAI-10) was used to assess attitudes towards antipsychotic medication [43].

\subsection{Healthcare resource use}

Use of resources (hospitalizations, emergency room visits, psychiatric outpatient consultations, other specialized outpatient consultations, and skilled nursing facilities), and non-pharmacologic therapies (e.g. institutional support, community treatment, rehabilitation and psychotherapy) were measured. Direct drug cost data were not collected.

\subsection{Patient subgroups}

Four predefined patient subgroups of interest were identified and analyzed if the subgroup represented $\geq 15 \%$ of the overall baseline population:

- Socially withdrawn patients: living alone or homeless, and/or no caregiver; or unemployed, with marital status defined as single, divorced/separated or widowed; or who scored "very severe" on item a (socially useful activities, including work and study) or b (personal and social relationships) of the PSP.

- Early in disease patients: aged $<35$ years, or with $<5$ years since diagnosis.

- High functioning and young patients: aged $\leq 35$ years with $<10$ years since diagnosis, high levels of insight (G12 PANSS scores of absent-to-mild), GAF scores $>61$, employed or studying, or living in an individual residence.

- Low functioning and chronic illness patients: aged $\geq 40$ years with $\geq 15$ years since diagnosis, lower levels of insight (PANSS G12 scores of moderate severe to extreme), GAF scores $<51$, unemployed or receiving a disability pension, or homeless/ institutionalized.

\subsection{Statistical analysis}

The baseline analysis population was defined as all patients who gave informed consent, met the selection criteria, and completed at least one baseline assessment. Analyses were performed using SAS ${ }^{\circledR}$ Version 9.2 and missing items were not imputed.

Categorical parameters are presented as the number of responses or percentage of patients in each category. Continuous parameters are reported as mean \pm SD. Secondary objectives, including identification of LAI user subgroups, were addressed by multiple correspondence analyses on intrinsic and extrinsic attributes important for LAI treatment choice.

\section{Results}

\subsection{Physician and site characteristics}

Overall, 177 physicians participated in the study. The majority were from the UK $(n=56)$, Germany $(n=46)$, Spain $(n=39)$, or
France $(n=28)$, with limited numbers from Austria $(n=5)$ and Sweden $(n=3)$. Physician age was $46.9 \pm 10.4$ years and $71.2 \%$ were male. Most physicians had $\geq 10$ years of psychiatrist experience (77.4\%; $18.3 \pm 9.9$ years). Most (82.1\%) of UK-based physicians worked for the National Health Service (NHS) exclusively and 51.2\% of physicians from other countries worked in an academic setting.

\subsection{Patient characteristics}

A total of 572/1482 screened patients were enrolled. Targets were met for prevalent FGA-LAI and SGA-LAI users (209/200 and $122 / 100$, respectively) but not for incident FGA-LAI (51/250; $20 \%$ of target) or SGA-LAI users (190/200; 95\% of target) (Fig. 1B).

Patient sociodemographics by country are summarized in Table 2. Most patients were from Germany, France, or the UK. Mean patient age was $44.0 \pm 13.2$ years and $67.3 \%$ were male. There were no significant gender differences between countries. Patients in Austria were on average younger than in other countries $(29.7 \pm 9.5$ years $)$. Most patients were single $(63.7 \%)$ and/or childless (88.6\%), unemployed (81.3\%) and/or classified as socially withdrawn (79.7\%). The majority lived in a household (86.4\%) and were considered autonomous with respect to eating or living conditions (84.8\%). The highest proportion of FGA-LAI users was in the UK (55.2\% prevalent and $11.7 \%$ incident FGA-LAI users, respectively) and the highest proportion of SGA-LAI users was in France (23.3\% prevalent and $43.2 \%$ incident SGA-LAI users, respectively, Supplementary Table 1 ).

Enrolled patients were diagnosed with schizophrenia at a mean age of $29.7 \pm 11.5$ years, with mean time since diagnosis of $13.4 \pm 11.3$ years. Overall, $37.2 \%$ were classified as early in disease; this group had few prevalent FGA-LAI users (Table 3). Incident LAI users generally had a shorter duration of disease in comparison with prevalent users and were more likely to have relapsed within the previous year (Table 3 ). Almost half of all patients had a history of substance abuse or dependence (49.5\%), and while considerable proportions suffered from comorbid mood or anxiety disorders ( $40.9 \%$ and $33.2 \%$, respectively) this was more likely in incident FGA-LAI users (Table 3).

Overall, $58.9 \%$ of patients were considered at risk of nonadherence (physician-rated), with the highest overall physicianrated risk observed in incident FGA-LAI users (82.4\%). Incident FGA-LAI users also had the highest rates of documented history of medication non-adherence (49.0\%), inadequate response to primary antipsychotic treatment (21.6\%), prior violent behavior (25.5\%), alcohol abuse (19.6\%), and drug abuse (29.4\%) (Supplementary Table 2).

\subsection{Treatment patterns}

At baseline, 56.4\% of incident LAI antipsychotic users commenced treatment with paliperidone, a SGA-LAI. Paliperidone was also the most commonly used drug for prevalent LAI users (20.5\%), and was prescribed to around one third of patients overall ( $\mathrm{n}$ $=204$ ). For a high proportion of prevalent SGA-LAI users on risperidone (74.4\%), this was the first LAI antipsychotic they had ever been prescribed, versus a smaller proportion for prevalent paliperidone users (36.8\%). The most common reason given for FGA-LAI prescription was poor compliance with the previous antipsychotic. Among LAI antipsychotic users, 39.9\% were also taking $\geq 1$ oral antipsychotic, with the highest incidence of comedication seen in incident FGA-LAI users (58.8\%).

In addition to LAI antipsychotics, $30.6 \%, 8.2 \%$, and $1.0 \%$ patients were receiving 1,2 , or $\geq 3$ oral antipsychotics, respectively. At least one other psychotropic medication was taken by $22.0 \%$ (antidepressants), 22.7\% (antiparkinsonians/anticholinergics), 25.9\% (anxiolytics), 9.6\% (mood stabilizers/anticonvulsants), and $14.0 \%$ 
Table 2

Patient Sociodemographics by Country.

\begin{tabular}{|c|c|c|c|c|c|c|c|}
\hline Characteristics & Austria $(n=7)$ & France $(n=146)$ & Germany $(n=164)$ & Spain $(n=89)$ & Sweden $(n=12)$ & UK $(n=154)$ & Overall $(\mathrm{N}=572)$ \\
\hline Age, mean, years (SD) & $29.7(9.5)$ & $40.3(12.3)$ & $46.9(12.5)$ & $45.4(11.5)$ & $46.3(16.9)$ & $44.0(14.5)$ & $44.0(13.2)$ \\
\hline Male, n (\%) & $5(71.4)$ & $106(72.6)$ & $92(56.1)$ & $54(60.7)$ & $10(83.3)$ & 118 (76.6) & $385(67.3)$ \\
\hline BMI, mean $(S D)^{a}$ & $27.2(6.7)$ & $25.8(4.9)$ & $28.9(5.5)$ & $28.7(6.9)$ & $28.2(6.4)$ & $28.4(7.1)$ & $27.9(6.2)$ \\
\hline \multicolumn{8}{|l|}{ Marital status, $\mathrm{n}(\%)^{\mathrm{b}}$} \\
\hline Observed & $7(100.0)$ & $146(100.0)$ & $163(99.4)$ & $89(100.0)$ & $11(91.7)$ & $154(100.0)$ & $570(99.7)$ \\
\hline Single & $6(85.7)$ & $98(67.1)$ & $86(52.8)$ & $62(69.7)$ & $9(81.8)$ & $102(66.2)$ & $363(63.7)$ \\
\hline Divorced/separated & $0(0.0)$ & $22(15.1)$ & $26(16.0)$ & $14(15.7)$ & $0(0.0)$ & $25(16.2)$ & $87(15.3)$ \\
\hline Married/living as a couple & $1(14.3)$ & $22(15.1)$ & $49(30.1)$ & $10(11.2)$ & $2(18.2)$ & $22(14.3)$ & $106(18.6)$ \\
\hline Widow & $0(0.0)$ & $1(0.7)$ & $1(0.6)$ & $3(3.4)$ & $0(0.0)$ & $4(2.6)$ & $9(1.6)$ \\
\hline Unknown & $0(0.0)$ & $3(2.1)$ & $1(0.6)$ & $0(0.0)$ & $0(0.0)$ & $1(0.6)$ & $5(0.9)$ \\
\hline \multicolumn{8}{|l|}{ Children living in the household $^{\mathrm{b}}$} \\
\hline Observed & $7(100.0)$ & $146(100.0)$ & $163(99.4)$ & $89(100.0)$ & $11(91.7)$ & $154(100.0)$ & $570(99.7)$ \\
\hline Yes, n $(\%)$ & $0(0.0)$ & $16(11.0)$ & $13(8.0)$ & $10(11.2)$ & $0(0.0)$ & $16(10.4)$ & $55(9.6)$ \\
\hline Mean number $(S D)^{c}$ & - & $1.9(1.2)$ & $1.5(0.7)$ & $1.2(0.6)$ & - & $2.2(1.9)$ & $1.7(1.3)$ \\
\hline \multicolumn{8}{|l|}{ Living area, $\mathrm{n}(\%)^{\mathrm{d}}$} \\
\hline Institutionalized & $0(0.0)$ & $13(9.0)$ & $8(4.9)$ & $5(5.7)$ & $1(8.3)$ & $23(14.9)$ & $50(8.8)$ \\
\hline Household & $7(100.0)$ & $129(89.0)$ & $142(87.7)$ & $81(92.0)$ & $11(91.7)$ & $121(78.6)$ & $491(86.4)$ \\
\hline Homeless & $0(0.0)$ & $1(0.7)$ & $10(6.2)$ & $2(2.3)$ & $0(0.0)$ & $9(5.8)$ & $22(3.9)$ \\
\hline Unknown & $0(0.0)$ & $2(1.4)$ & $2(1.2)$ & $0(0.0)$ & $0(0.0)$ & $1(0.6)$ & $5(0.9)$ \\
\hline \multicolumn{8}{|c|}{ Educational status (highest completed level), n (\%) } \\
\hline None & $0(0.0)$ & $0(0.0)$ & $2(1.2)$ & $3(3.4)$ & $0(0.0)$ & $2(1.3)$ & $7(1.3)$ \\
\hline Primary to High School & $5(71.4)$ & $91(64.1)$ & $131(81.4)$ & $76(87.4)$ & $3(30.0)$ & $108(70.6)$ & $414(73.9)$ \\
\hline Beyond High School & $2(28.6)$ & $37(26.1)$ & $22(13.7)$ & $8(9.2)$ & $7(70.0)$ & $28(18.3)$ & $104(18.6)$ \\
\hline Unknown & $0(0.0)$ & $14(9.9)$ & $6(3.7)$ & $0(0.0)$ & $0(0.0)$ & $15(9.8)$ & $35(6.3)$ \\
\hline \multicolumn{8}{|l|}{ Professional status, n (\%) } \\
\hline Employed/student/voluntary & $4(57.1)$ & $30(20.6)$ & $38(23.2)$ & $14(15.7)$ & $3(25.0)$ & $14(9.1)$ & $103(18.0)$ \\
\hline Unemployed & $3(42.9)$ & $116(79.5)$ & $125(76.2)$ & $74(83.2)$ & $9(75.0)$ & $138(89.6)$ & $465(81.3)$ \\
\hline Unknown & $0(0.0)$ & $0(0.0)$ & $1(0.6)$ & $1(1.1)$ & $0(0.0)$ & $2(1.3)$ & $4(0.7)$ \\
\hline \multicolumn{8}{|l|}{ Socially withdrawn status, n (\%) } \\
\hline Yes & $6(85.7)$ & $118(80.8)$ & $133(81.1)$ & $57(64.0)$ & $11(91.7)$ & $131(85.1)$ & $456(79.7)$ \\
\hline
\end{tabular}

BMI: body mass index, SD: standard deviation.

a Overall $n=490$; Germany $n=151$; UK $n=114$; France $n=128$; Spain $n=79$; Sweden $n=11$.

b Overall $n=570$; Germany $n=163$; Sweden $n=11$.

c Of those who have children in the household.

d Overall $n=568$; Germany $n=162$; France $n=145$; Spain $n=88$.

e Overall $n=560$; Germany $n=161$; UK $n=153$; France $n=142$; Spain $n=87$; Sweden $n=10$.

(hypnotics) of patients. Proportions of patients that were being treated with other psychotropic medications were similar between FGA- and SGA-LAI incident users for anti-depressants, anxiolytics and mood stabilizers/anticonvulsants. A greater proportion of incident FGA-LAI users than incident SGA-LAI users were receiving treatment with antiparkinsonian/anticholinergic medications (39.2\% vs $12.6 \%$, respectively, Supplementary Table 4 ).

\subsection{Side effects}

Side effects data were collected for incident users at the time of change of treatment. Among the non-missing UKU assessments conducted for incident users ( $n=216,89.6 \%$ ), side effects were reported in $68.1 \%$ of patients $(147 / 216)$; with slightly more in FGA-LAI users $(n=34 ; 66.7 \%)$ than in SGA-LAI users $(n=113$; 59.5\%) (Supplementary Table 5). Causality of side effects was rated as "possible" or "probable" and severity was assessed as mild-to-severe. The most commonly reported side effects fell within the Psychic domain and included concentration difficulties (14.1\% of completed assessments for incident FGA-LAI users, $14.4 \%$ for SGA-LAI users) and lassitude (14.1\% for incident FGA-LAI users, $14.4 \%$ for SGA-LAI users). There were fewer reports of tremor from incident FGA-LAI users than incident SGA-LAI users (8.8\% vs $21.4 \%$ of completed assessments; Supplementary Table 5).

\subsection{Patient- and physician-reported clinical assessments}

CGI-S score indicated disease severity across patient groups was mild-to-moderate $(60.8 \%$ of patients, mean score 3.8$)$. A higher proportion of incident users were in the markedly or severely ill category (Fig. 2A).

Overall PSP score was $58.1 \pm 17.3$ (Fig. 2B), indicating marked difficulties in social functioning for $58.8 \%$ of the cohort. In addition, $17.6 \%$ of patients had severe difficulties in social functioning and 23.7\% mild difficulties. There was a notable difference between incident and prevalent user PSP scores; incident users generally scored lower in global functioning (Fig. 2B). Across incident and prevalent categories, FGA-LAI users scored lower in social and personal functioning than SGA-LAI users, and incident FGA-LAI users had the most severe functioning deficits.

Mean GAF score was $57.9 \pm 16.6$, rating the patients with moderate symptoms (Fig. 2C). Irrespective of incident/prevalent category, users of FGA- were more severe compared to SGA-LAI users, and the incident FGA-LAI users were most severe in global functioning (Fig. 2C).

Between-group differences in insight, measured by the PANSS G12, appeared more driven by incident/prevalent status than by SGA-LAI/FGA-LAI status, and prevalent users tended towards better levels of insight (Fig. 2D). The proportions of patients for whom lack of judgment and insight was 'absent' or 'minimal' (i.e. no/little perceived problem) were $44.8 \%$ and $41.3 \%$ for prevalent FGA- and SGA-LAI users respectively, compared with $34.0 \%$ and $24.6 \%$ for incident FGA- and SGA-LAI users, respectively. The proportions of patients for whom lack of judgment and insight was 'moderate severe' or 'severe' were $17.4 \%$ and $11.5 \%$ for prevalent FGA- and SGA-LAI users, compared with $32.0 \%$ and $23.5 \%$ for incident FGA- and SGA-LAI users, respectively. Very few patients $(0.5 \%)$ were perceived to have 'extreme' lack of judgment or insight. There was no discernible pattern in the patient-scored IS 
Table 3

Patient Characteristics and Selected Sociodemographics by LAI Use.

\begin{tabular}{|c|c|c|c|c|c|c|}
\hline $\begin{array}{l}\text { Characteristics, \% } \\
\text { (unless otherwise indicated) }\end{array}$ & $\begin{array}{l}\text { Prevalent FGA-LAI } \\
(\mathrm{n}=209)\end{array}$ & $\begin{array}{l}\text { Prevalent SGA-LAI } \\
(\mathrm{n}=122)\end{array}$ & $\begin{array}{l}\text { Incident FGA-LAI } \\
(\mathrm{n}=51)\end{array}$ & $\begin{array}{l}\text { Incident SGA-LAI } \\
(\mathrm{n}=190)\end{array}$ & $\begin{array}{l}\text { Overall } \\
(\mathrm{N}=572)\end{array}$ & $\mathrm{p}$ value $^{\mathrm{a}}$ \\
\hline Age, mean, years & 47.9 & 42.9 & 38.0 & 42.0 & 44.0 & $<0.0001$ \\
\hline Unemployed & 88.5 & 76.2 & 78.4 & 77.4 & 81.3 & - \\
\hline Institutionalized & $13.0^{\mathrm{b}}$ & $3.3^{\mathrm{c}}$ & $3.9^{\mathrm{d}}$ & $9.0^{\mathrm{e}}$ & $8.8^{\mathrm{f}}$ & - \\
\hline Age at 1 st diagnosis, mean, years & $30.4^{\mathrm{g}}$ & $29.8^{\mathrm{h}}$ & $28.2^{\mathrm{i}}$ & $29.4^{\mathrm{j}}$ & $29.7^{\mathrm{k}}$ & 0.6577 \\
\hline Time since diagnosis, mean, years & $16.7^{\mathrm{g}}$ & $12.5^{\mathrm{h}}$ & $9.9^{\mathrm{i}}$ & $11.3^{\mathrm{j}}$ & $13.4^{\mathrm{k}}$ & $<0.0001$ \\
\hline Early in disease & 22.0 & 42.6 & 47.1 & 47.9 & 37.2 & $<0.0001$ \\
\hline Socially withdrawn ${ }^{1}$ & 79.9 & 84.4 & 76.5 & 77.4 & 79.7 & 0.4473 \\
\hline Previous relapses in the past year & 27.3 & 31.1 & 45.1 & 49.5 & 37.1 & $<0.0001$ \\
\hline$\geq 1$ previous suicide attempt & 29.7 & 16.4 & 15.7 & 17.9 & 21.7 & - \\
\hline $\begin{array}{l}\text { Previous suicide attempts in the past } \\
\text { year }\end{array}$ & 5.7 & 1.6 & 7.8 & 5.8 & 5.1 & 0.0965 \\
\hline Mood disorders & $38.6^{\mathrm{m}}$ & 40.2 & 54.9 & 40.0 & $40.9^{n}$ & - \\
\hline Depressive comorbidity & 55.5 & 51.6 & 58.8 & 50.0 & 53.1 & - \\
\hline Anxiety disorders & $28.5^{\mathrm{m}}$ & 32.8 & 51.0 & 33.7 & $33.2^{\mathrm{n}}$ & - \\
\hline Substance abuse/dependence & $53.1^{\mathrm{m}}$ & 42.6 & 64.7 & 45.8 & $49.5^{n}$ & - \\
\hline Other psychiatric comorbidities & $24.2^{\mathrm{m}}$ & 18.0 & 19.6 & 18.4 & $20.5^{n}$ & - \\
\hline Metabolic disorders & $20.7^{b}$ & 18.0 & 7.8 & 13.7 & $16.6^{\circ}$ & - \\
\hline Diabetes mellitus & $11.1^{\mathrm{b}}$ & 5.7 & 7.8 & 4.7 & $7.5^{\circ}$ & - \\
\hline Neurologic disorders & $18.3^{\mathrm{b}}$ & 7.4 & 9.8 & 10.5 & $12.6^{\circ}$ & - \\
\hline Mainly previously treated by oral ${ }^{\circ}$ & 0.5 & 2.5 & 21.6 & 31.1 & 12.9 & - \\
\hline Mainly previously treated by $\mathrm{LAI}^{\mathrm{P}}$ & 92.8 & 82.0 & 17.7 & 12.6 & 57.2 & - \\
\hline Mainly untreated ${ }^{\mathrm{q}}$ & 6.7 & 15.6 & 60.8 & 56.3 & 29.9 & - \\
\hline Ever treated with clozapine & $10.6^{\mathrm{n}}$ & 9.8 & 9.8 & 6.8 & $9.1^{\mathrm{n}}$ & - \\
\hline Last used AP was FGA-LAI & 19.1 & 5.7 & 9.8 & 13.2 & 13.5 & - \\
\hline Last used AP was SGA-LAI & 6.2 & 27.0 & 25.5 & 12.6 & 14.5 & - \\
\hline Last used AP was oral & 36.4 & 52.5 & 66.7 & 83.7 & 58.2 & - \\
\hline
\end{tabular}

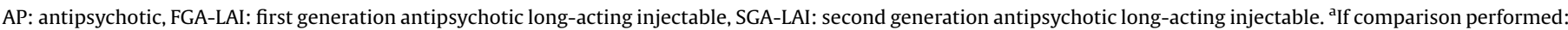

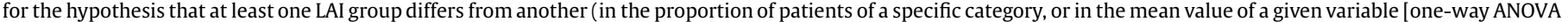

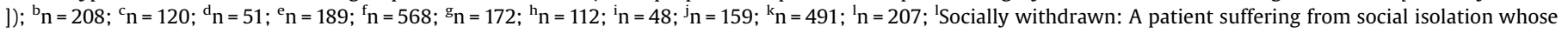

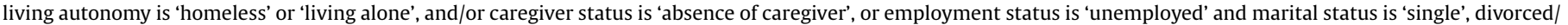

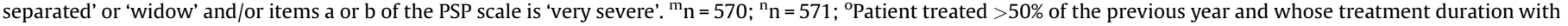

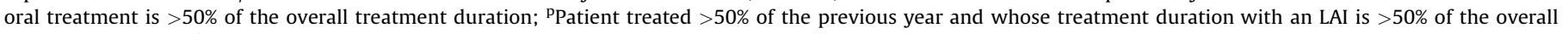
treatment duration; ${ }^{9}$ Patient whose treatment duration is $\leq 50 \%$ of the previous year.

results; the lowest insight here was observed in prevalent SGA-LAI users (Fig. 2H).

A good level of well-being was suggested across all groups; mean SWN-S score ranged from 76.8 to 86.3 (Fig. 2E). According to SWN-S and TooL measures, patients initiating SGA-LAIs had better quality of life scores than those initiating FGA-LAIs. Incident FGALAI users had the lowest quality of life (Fig. 2E and F).

Patient attitudes towards medication (DAI-10 scores) were more positive in prevalent than incident users. These results corresponded to the physician-assessed risk of non-adherence (highest risk in incident FGA-LAI users [82.4\%], followed by incident SGA-LAI users [58.4\%], and prevalent users [FGA-LAI: 56.9\%; SGA-LAI: 53.3\%], Fig. 2G).

\subsection{Healthcare resource use}

In the previous year, $36.3 \%$ of patients had $\geq 1$ hospitalization, mainly due to schizophrenia (93.7\%). Incident FGA-LAI users had the highest rate of hospitalization (52.9\%). Overall, $82.2 \%$ of patients had $\geq 1$ psychiatrist visit and $51.6 \%$ had $\geq 1$ GP visit within the past year. The highest proportion of hospitalized patients at baseline was in the UK $(82 / 154,53.6 \%)$ while none were hospitalized in Sweden. The longest stay per patient was in the UK (71.4 days), and shortest in Spain (33.3 days). The average number of psychiatrist visits was highest in France $(10.8 \pm 8.7)$ and lowest in Sweden $(2.3 \pm 0.9)$. In the previous year, $>90 \%$ of patients from the UK and Sweden had used other healthcare professionals or community services, while only $26.2 \%$ of patients in Germany utilized these resources.

\subsection{Patient subgroups}

The proportions of patients in different subgroups varied between countries (Supplementary Table 3). For most patients in all countries except the UK (48.1\%) and Spain (49.4\%), the studied treatment was their first LAI antipsychotic. Spain had the lowest proportion of socially withdrawn patients ( $64.0 \%$; versus $>80 \%$ in all other countries). The highest proportion of early in disease patients was observed in Austria (5/7 patients, $71.4 \%$ ), and the lowest in Germany (44/164 patients, $26.8 \%$ ).

When analyzed by LAI antipsychotic user group, incident SGALAI users had the highest proportion of LAI antipsychotic-naïve patients. The highest proportion of high functioning and young patients was observed in prevalent SGA-LAI users (16.4\%, versus $9.8 \%$ overall). The highest proportion of low functioning and chronic patients was observed among incident FGA-LAI users (11.8\%, versus $7.0 \%$ overall).

\section{Discussion}

European research examining sociodemographic characteristics, and treatment outcomes of patients receiving FGA- and SGALAIs is limited, with studies confined to 1 country, the effects of only 1 type of LAI, or 1 patient group [14,44,45]. Considerable variability also exists in tools used to evaluate functioning, quality of life, insight and attitudes, and the collection of patient versus physician data [2].

ALTO was the first large-scale study to report multinational results on both FGA- and SGA-LAI use in different countries in Europe. The baseline data indicates a lower pattern of FGA-LAI usage, with these drugs being reserved for seemingly more difficult-to-treat patients and those least likely to adhere to oral therapy. Patients treated with FGA-LAIs tended to have more severe disease, poorer global functioning, and were more likely to have moderate-to-severe, or severe lack of insight as reported by their physician, compared with those treated with SGA-LAIs. This was most pronounced for incident FGA-LAI users, who were also 
A - Severity of Illness: CGI-S

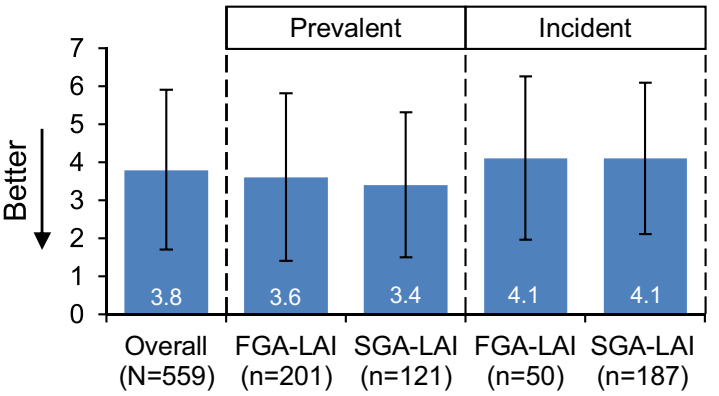

\section{B - Functioning: PSP}

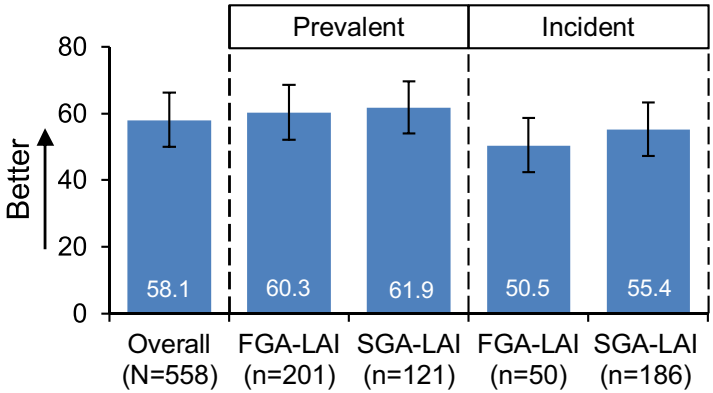

\section{C - Functioning: GAF}

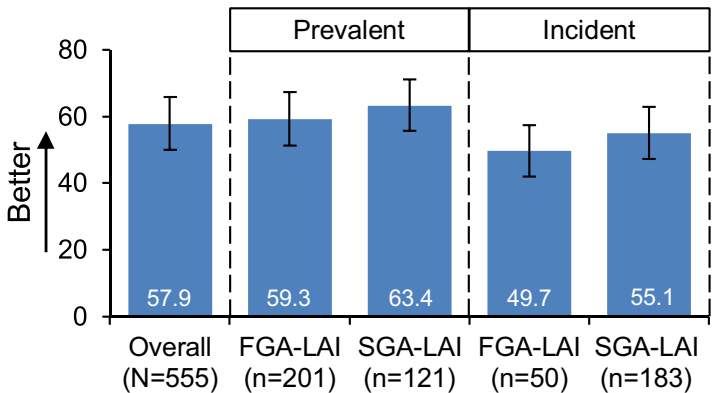

\section{D - Insight: PANSS G12}

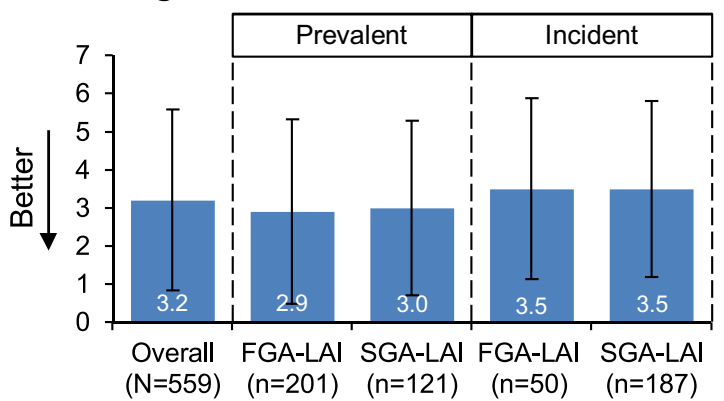

\section{E - Quality of Life: SWN-S}

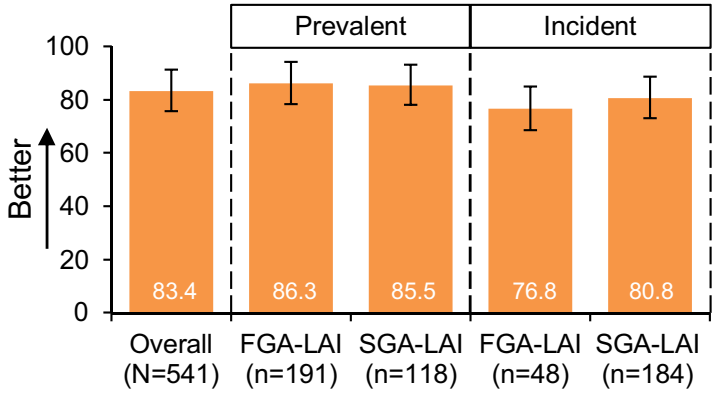

F - Quality of Life: TooL

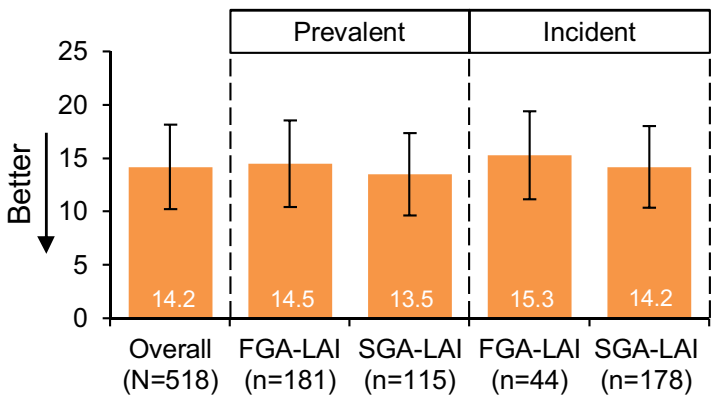

G - Attitudes to Treatment: DAI-10

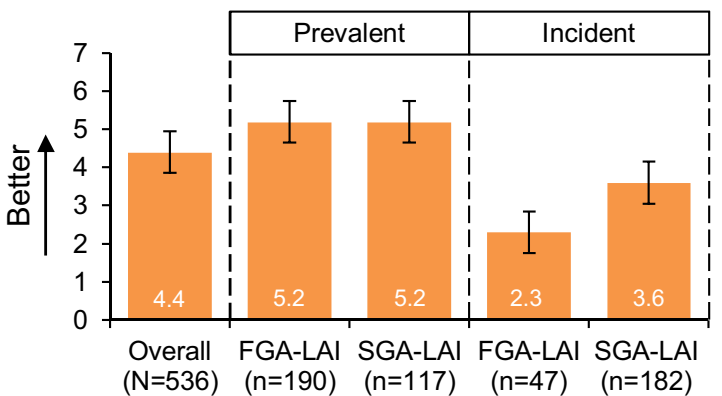

H - Insight: Insight Scale

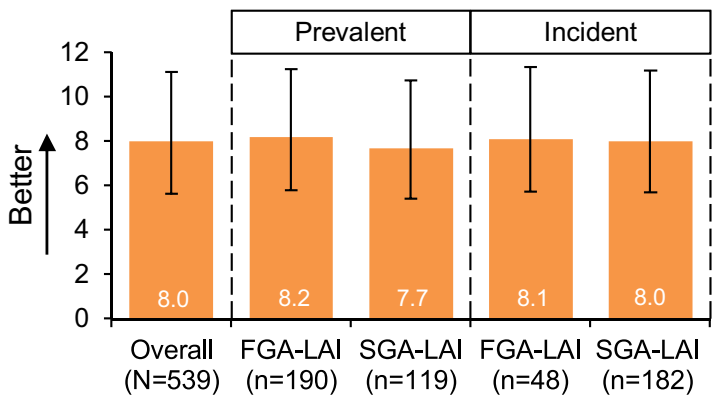

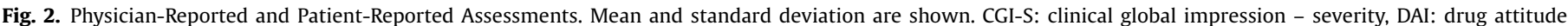

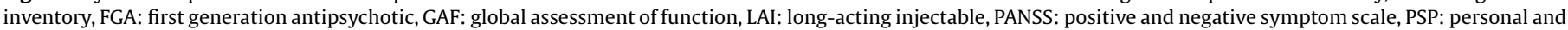
social performance, SGA: second generation antipsychotic, SWN-S: subjective well-being under neuroleptic scale, TooL: tolerability and quality of life.

considered at greatest risk of non-adherence. Prevalent LAI users tended towards better levels of insight and this appeared driven more by incident/prevalent status than by SGA-/FGA-LAI status, which may be expected as incident users were not treated with LAIs at the time of enrollment.
Sociodemographic and clinical characteristics of the ALTO baseline population were similar to previously described populations of patients with schizophrenia [7,46]. Additionally, the average severity of disease was comparable to that reported in other regional studies (Europe, Asia-Pacific, Central America, and 
the United States) [10,46-48]. However, the proportion of patients with a history of substance abuse was higher in our study population (49.5\%) [46]. Average age at first schizophrenic episode was estimated to be 30 years old - slightly older than in other published studies (24 and 27 in the Bernado et al [46] and Jaegar and Rossler [7] studies, respectively). As expected, LAI incident users tended to have a more recent diagnosis of schizophrenia, and a history of relapse in the previous year as compared to the prevalent LAI users [16].

In our study, $22.7 \%$ of patients were receiving antiparkinsonians/anticholinergics, treatment with which is a commonly used proxy for extra-pyramidal side effects induced by anti-psychotics [49]. In our study, fewer incident FGA-LAI users reported occurrence of tremor than incident SGA-LAI users. This could be explained by the fact that a greater proportion of incident FGA-LAI users were being treated with antiparkinsonian/anticholinergic psychotropic medications than incident SGA-LAI users.

The characteristics of physicians participating in this study were also similar in patterns of age, mean years of experience and gender to previous studies [21,50]. This is important as earlier research has shown that physician characteristics may influence the selection of a FGA-LAI (associated with greater physician age and employment in private practice) [51].

Unlike other published studies reporting low or even negative DAI-10 scores $[10,46]$, the mean DAI-10 score for the overall ALTO study population represented a moderate subjective positive attitude to LAI treatment and suggested a lower than expected rate of non-adherence in our study population. Although $58.9 \%$ of the study population was considered at risk of non-adherence at baseline, this was only documented for $37 \%$ of patients. Previous reports suggest that rates of non-adherence to antipsychotics in patients with schizophrenia vary significantly (between 30\% and 60\%) and depend on the definition of non-adherence [4,52-55]. However, the ALTO study is the first to involve a multinational sample of prescribers in Europe, which may make meaningful comparisons difficult. Furthermore, the relatively low rate of non-adherence observed here may not be surprising considering LAI antipsychotic treatment is associated with reduced risk of non-adherence [21], and that our sample of physicians may be more open to the use of LAI antipsychotics (as indicated by provider site commitment to patient recruitment). It may also be that LAIs are considered the preferred, most convenient option for patients [56,57], and improve the patientcaregiver relationship.

Differences in hospitalization, length of hospital stay, visits to psychiatrists, and additional visits to community services are most likely influenced by country-specific healthcare provisions. Cultural differences between the different European countries may also influence communication, symptom manifestation, patient coping styles, community support systems, and willingness to seek and maintain treatment $[58,59]$. There may also be treatment centerspecific differences, including treatment practices and differences in recommendation lists and local formularies that may impact the level of LAI antipsychotic prescription. Other factors pertaining to country-specific culture and sites, as well as physician training, knowledge and support may also influence prescription patterns of LAI antipsychotics, as highlighted previously [21].

Among the limitations of this study is the representativeness of data for Sweden and Austria. There was also a difference in work settings of the physicians that participated in the ALTO study; most UK-based physicians worked exclusively within the NHS while around half of physicians from other countries worked in an academic setting. Additionally, incident FGA-LAI users were underrepresented compared to other LAI antipsychotic user groups - possibly due to a naturalistic change in LAI antipsychotic prescription patterns in Europe with an evolution of preference for
SGA- over FGA-LAIs [60]. The low numbers of patients prescribed FGA-LAIs may also be attributable to non-participation of forensic providers in this study. Our prescriber sample may have been more predisposed to prescription of LAI antipsychotics, which may have an additional associated bias in favour of SGA-LAI prescribing. Although the lower numbers in this LAI-user group could trigger selection bias in the results, the baseline characteristics of these patients are consistent with previous studies.

Although LAIs were specifically developed to promote treatment adherence, gaps in knowledge and evidence surrounding their appropriate usage remains. Improvements in psychopharmacology and a focus on patient experience could help improve attitudes towards and appropriate use of LAI antipsychotics [19,61]. Results from the cross-sectional part of the ALTO study indicate a lower pattern of FGA-LAI prescription to patients in Europe. Due to a paucity of data, the reasons for this remain unclear, however it may be that FGA-LAI may tend to be used in patients with more severe disease $[21,62]$. They highlight the necessity for further research to promote the evidence-based, appropriate use of LAI antipsychotics for schizophrenia treatment and will be complemented by results from the longitudinal portion of the ALTO study.

\section{Role of the funding source}

The ALTO Study (No. 14782A) was funded by H. Lundbeck A/S, 2500 Valby, Denmark. The implementation and conduct of this study, including statistical analysis, was undertaken by QuintilesIMS and led by Kari Kastango (Director of Biostatistics, QuintilesIMS). The study protocol is available from AGN@lundbeck. com.

\section{Contributions}

All authors provided substantial contributions to study conception/design or acquisition/analysis/interpretation of data, and drafted or revised the publication critically for important, intellectual content. All authors approved the final manuscript.

\section{Conflict of interest}

PML: reports compensation from Lundbeck for travel and time related to this study scientific board, honorarium and fees for advisory board and as a speaker from Eli-Lilly, Janssen, Lundbeck, Otsuka and Teva, JB: reports compensation from Lundbeck for travel and time related to this study scientific board, WF: reports compensation from Lundbeck for travel and time related to this study scientific board, SH: reports compensation from Lundbeck for travel and time related to this study scientific board, has received speaker honoraria from Janssen-Cilag, Eli Lilly, SanofiAventis, Otsuka, Lundbeck and Johnson \& Johnson, has accepted travel or hospitality payment from Janssen-Cilag, Sanofi-Aventis, Johnson \& Johnson, Pfizer, Bristol-Myers-Squibb, AstraZeneca, Lundbeck, Novartis and Eli Lilly, has participated in clinical trials sponsored or supported by Eli Lilly, Janssen Cilag, Johnson \& Johnson, Bristol-Myers-Squibb, AstraZeneca, Lundbeck, Novartis, Servier, Pierre Fabre, Pfizer, Organon, Roche and Merck, and has received honoraria for participation in advisory-boards or activities as a consultant from Lundbeck, Otsuka, Eli Lilly, Roche, Teva, Janssen and Johnson \& Johnson, NM: reports compensation from Lundbeck for travel and time related to this study scientific board. No other conflicts reported for this study. Bordeaux PharmacoEpi has research contracts with most pharmaceutical companies, but none in the field of psychopharmacology, NB-E: Full-time employee of Lundbeck SAS at time of research, CS: Full-time employee of Lundbeck SAS at time of research, J-YL: Employee of Otsuka, A-GN: Employee of Lundbeck SAS, MXP: has received 
honoraria for activities as a consultant for, and accepted travel or hospitality payment from, Otsuka, Sunovion, Janssen, Lundbeck, Lilly, Boehringer-Ingelheim, Endo and Wyeth, as a speaker for Otsuka, Lundbeck, Janssen and Lilly, and has participated in clinical trials and studies for Janssen, Takeda, Lundbeck and Amgen and reports compensation from Lundbeck for travel and time related to this study scientific board.

\section{Acknowledgements}

The authors acknowledge Pedro Such from H. Lundbeck A/S, Denmark, for publication coordination, and Debbie Nixon, DPhil, and Ruth Le Fevre, PhD, from Costello Medical, UK, for writing and editorial assistance. This study was sponsored by $\mathrm{H}$. Lundbeck A/S, 2500 Valby (Copenhagen), Denmark.

\section{Appendix A. Supplementary data}

Supplementary data associated with this article can be found, in the online version, at https://doi.org/10.1016/j.eurpsy.2018.04.004.

\section{References}

[1] Castillo E.G., Stroup TS. Effectiveness of long-acting injectable antipsychotics: a clinical perspective. Evid-Based Mental Health 2015;18(2):36-9.

[2] Nasrallah HA, Harvey PD, Casey D, Csoboth CT, Hudson JI, Julian L, et al. The Management of Schizophrenia in Clinical Practice (MOSAIC) Registry: a focus on patients, caregivers, illness severity, functional status, disease burden and healthcare utilization. Schizophr Res 2015;166(1-3):69-79.

[3] Schultz SH, North SW, Shields CG. Schizophrenia: a review. Am Fam Physician 2007;75(12):1821-9.

[4] Kane JM. Review of treatments that can ameliorate nonadherence in patients with schizophrenia. J Clin Psychiatry 2006;67(Suppl. 5):9-14.

[5] Nasrallah HA, Lasser R. Improving patient outcomes in schizophrenia: achieving remission. J Psychopharm (Oxf, Engl) 2006;20(6 Suppl):57-61.

[6] Ciudad A, Haro JM, Alonso J, Bousono M, Suarez D, Novick D, et al. The Schizophrenia Outpatient Health Outcomes (SOHO) study: 3-year results of antipsychotic treatment discontinuation and related clinical factors in Spain European psychiatry. J Assoc Eur Psychiatr 2008;23(1):1-7.

[7] Jaeger M, Rossler W. Attitudes towards long-acting depot antipsychotics: a survey of patients, relatives and psychiatrists. Psychiatry Res 2010;175(12):58-62.

[8] Buckley PF, Wirshing DA, Bhushan P, Pierre JM, Resnick SA, Wirshing WC. Lack of insight in schizophrenia. CNS Drugs 2007;21(2):129-41.

[9] Patel MX, David AS. Medication adherence: predictive factors and enhancement strategies. Psychiatry 2007;6(9):357-61.

[10] Brnabic AJ, Kelin K, Ascher-Svanum H, Montgomery W, Kadziola Z, Karagianis J. Medication discontinuation with depot and oral antipsychotics in outpatients with schizophrenia: comparison of matched cohorts from a 12-month observational study. Int J Clin Pract 2011:65(9):945-53.

[11] Patel MX, Taylor M, David AS. Antipsychotic long-acting injections: mind the gap. Br J Psychiatry Supp 2009;52:S1-4.

[12] Zhu B, Ascher-Svanum H, Shi L, Faries D, Montgomery W, Marder SR. Time to discontinuation of depot and oral first-generation antipsychotics in the usual care of schizophrenia. Psychiatr Serv (Washington, DC) 2008;59 (3):315-7.

[13] Kishimoto T, Nitta M, Borenstein M, Kane JM, Correll CU. Long-acting injectable versus oral antipsychotics in schizophrenia: a systematic review and metaanalysis of mirror-image studies. J Clin Psychiatry 2013;74(10):957-65.

[14] Olivares JM, Rodriguez-Morales A, Diels J, Povey M, Jacobs A, Zhao Z, et al. Long-term outcomes in patients with schizophrenia treated with risperidone long-acting injection or oral antipsychotics in Spain: results from the electronic Schizophrenia Treatment Adherence Registry (e-STAR). Eur Psychiatry: J Assoc Eur Psychiatr 2009;24(5):287-96.

[15] Tiihonen J, Haukka J, Taylor M, Haddad PM, Patel MX, Korhonen P. A nationwide cohort study of oral and depot antipsychotics after first hospitalization for schizophrenia. Am J Psychiatry 2011;168(6):603-9.

[16] Tiihonen J, Mittendorfer-Rutz E, Majak M, Mehtala J, Hoti F, Jedenius E, et al Real-world effectiveness of antipsychotic treatments in a nationwide cohort of 29823 patients with schizophrenia. JAMA Psychiatry 2017;74(7):686-93.

[17] Kirson NY, Weiden PJ, Yermakov S, Huang W, Samuelson T, Offord SJ, et al. Efficacy and effectiveness of depot versus oral antipsychotics in schizophrenia: synthesizing results across different research designs. J Clin Psychiatry 2013;74(6):568-75.

[18] Haddad PM, Taylor M, Niaz OS. First-generation antipsychotic long-acting injections v: oral antipsychotics in schizophrenia: systematic review of randomised controlled trials and observational studies. Br J Psychiatry Suppl 2009;52:S20-8.
[19] Patel MX, Bishara D, Jayakumar S, Zalewska K, Shiers D, Crawford MJ, et al. Quality of prescribing for schizophrenia: evidence from a national audit in England and Wales. Eur Neuropsychopharmacol: J Eur Coll Neuropsychopharmacol 2014;24(4):499-509.

[20] Taylor D. Psychopharmacology and adverse effects of antipsychotic longacting injections: a review. Br J Psychiatry Suppl 2009;52:S13-9.

[21] Patel MX, Haddad PM, Chaudhry IB, McLoughlin S, Husain N, David AS. Psychiatrists' use, knowledge and attitudes to first- and second-generation antipsychotic long-acting injections: comparisons over 5 years. J Psychopharmacol (Oxf Engl) 2010;24(10):1473-82.

[22] Brissos S, Veguilla MR, Taylor D, Balanza-Martinez V. The role of long-acting injectable antipsychotics in schizophrenia: a critical appraisal. Ther Adv Psychopharmacol 2014;4(5):198-219.

[23] Miles SW, Wheeler A, Davies K. Determining what practising clinicians believe about long-acting injectable antipsychotic medication. Int J Psychiatry Clin Pract $2011 ; 15(2): 135-44$.

[24] Murray CJL, Lopez AD. The global burden of disease - a comprehensive assessment of mortality and disability form diseases, injuries and risk factors in 1990 and projected to 2020. Cambridge, MA: Harvard School of Public Health; 1996.

[25] The European Medicines Agency. The US Food and Drug Administration. Terms of reference for the EMA/FDA cluster on patient engagement. 2016 Available online at: http://www.ema.europa.eu/docs/en_GB/document_library/Other/ 2016/06/WC500209197.pdf.

[26] Catala-Lopez F, Hutton B, Page MJ, Vieta E, Tabares-Seisdedos R, Moher D. Declaration of transparency: a step towards complete reporting of research articles. Revista de psiquiatria y salud mental 2016;9(1):63-4.

[27] Catala-Lopez F, Moher D, Tabares-Seisdedos R. Improving transparency of scientific reporting to increase value and reduce waste in mental health research. Revista de psiquiatria y salud mental 2016;9(1):1-3.

[28] Karow A, Czekalla J, Dittmann RW, Schacht A, Wagner T, Lambert M, et al. Association of subjective well-being, symptoms, and side effects with compliance after 12 months of treatment in schizophrenia. J Clin Psychiatry 2007;68(1):75-80.

[29] Lambert M, Schimmelmann BG, Schacht A, Karow A, Wagner T, Wehmeier PM, et al. Long-term patterns of subjective wellbeing in schizophrenia: cluster, predictors of cluster affiliation, and their relation to recovery criteria in 2842 patients followed over 3 years. Schizophr Res 2009;107(2-3):165-72.

[30] Lambert M, Schimmelmann BG, Schacht A, Suarez D, Haro JM, Novick D, et al. Differential 3-year effects of first- versus second-generation antipsychotics on subjective well-being in schizophrenia using marginal structural models. J Clin Psychopharmacol 2011;31(2):226-30.

[31] AstraZeneca Study Registry. QUALITY: a non-interventional study evaluating quality of Life in schizophrenic patients treated with atypical antipsychotics, in the ambulatory setting. A 9-month, observational, multicentric prospective study. Clinical Study Report NIS-NBE-SER-2006/1. 2010.

[32] AstraZeneca Study Registry. XPERIENCE: a non-interventional study evaluating well-being/quality of life in schizophrenic patients treated with Seroquel $\mathrm{XR}^{\mathbb{R}}$ (quetiapine) and other atypical antipsychotics. A 9-month, observational, multicentric prospective study. Clinical Study Report NIS-NNLSER-2008/1. 2011.

[33] Wehmeier PM, Kluge M, Schneider E, Schacht A, Wagner T, Schreiber W. Quality of life and subjective well-being during treatment with antipsychotics in out-patients with schizophrenia. Prog Neuro-Psychopharmacol Biol Psychiatry 2007;31(3):703-12.

[34] AstraZeneca Study Registry. Observational and prospective study about the progress of subjective well-being in patients with schizophrenia: 4D study. Clinical Study Report NIS-NES-DUM-2008/2. 2010.

[35] Lingjaerde O, Ahlfors UG, Bech P, Dencker SJ, Elgen K. The UKU side effect rating scale. A new comprehensive rating scale for psychotropic drugs and a cross-sectional study of side effects in neuroleptic-treated patients. Acta Psychiatr Scand Suppl 1987;334:1-100.

[36] Busner J, Targum SD. The clinical global impressions scale: applying a research tool in clinical practice. Psychiatry (Edgmont) 2007;4(7):28-37.

[37] Pinna F, Deriu L, Diana E, Perra V, Randaccio RP, Sanna L, et al. Clinical Global Impression-severity score as a reliable measure for routine evaluation of remission in schizophrenia and schizoaffective disorders. Ann Gen Psychiatry 2015;14:6.

[38] Morosini PL, Magliano L, Brambilla L, Ugolini S, Pioli R. Development, reliability and acceptability of a new version of the DSM-IV Social and Occupational Functioning Assessment Scale (SOFAS) to assess routine social functioning. Acta Psychiatr Scand 2000;101(4):323-9.

[39] Kay SR, Fiszbein A, Opler LA. The positive and negative syndrome scale (PANSS) for schizophrenia. Schizophr Bull 1987:13(2):261-76.

[40] Birchwood M, Smith J, Drury V, Healy J, Macmillan F, Slade M. A self-report Insight Scale for psychosis: reliability, validity and sensitivity to change. Acta Psychiatr Scand 1994;89(1):62-7.

[41] Naber D, Moritz S, Lambert M, Pajonk FG, Holzbach R, Mass R, et al. Improvement of schizophrenic patients' subjective well-being under atypical antipsychotic drugs. Schizophr Res 2001;50(1-2):79-88.

[42] Lindström E, Jönsson L, Berntsson A. A patient perspective on side effects of antipsychotic therapy: the TOOL instrument. Value Health 2009;12:A361.

[43] Sendt KV, Tracy DK, Bhattacharyya S. A systematic review of factors influencing adherence to antipsychotic medication in schizophreniaspectrum disorders. Psychiatry Res 2015;225(1-2):14-30. 
[44] De la Gandara J, San Molina L, Rubio G, Rodriguez-Morales A, Hidalgo Borrajo R, Buron JA. Experience with injectable long-acting risperidone in long-term therapy after an acute episode of schizophrenia: the SPHERE Study. Expert Rev Neurother 2009;9(10):1463-74.

[45] Grimaldi-Bensouda L, Rouillon F, Astruc B, Rossignol M, Benichou J, Falissard B, et al. Does long-acting injectable risperidone make a difference to the real-life treatment of schizophrenia? Results of the Cohort for the General study of Schizophrenia (CGS). Schizophr Res 2012;134(2-3):187-94.

[46] Bernardo M, San L, Olivares JM, Dilla T, Polavieja P, Gilaberte I, et al. Treatment patterns and health care resource utilization in a 1-year observational cohort study of outpatients with schizophrenia at risk of nonadherence treated with long-acting injectable antipsychotics. Patient Preference Adherence 2011;5:601-10.

[47] Lambert T, Olivares JM, Peuskens J, DeSouza C, Kozma CM, Otten P, et al. Effectiveness of injectable risperidone long-acting therapy for schizophrenia: data from the US, Spain, Australia, and Belgium. Ann Gen Psychiatry 2011;10:10.

[48] Macfadden W, DeSouza C, Crivera C, Kozma CM, Dirani RD, Mao L, et al. Assessment of effectiveness measures in patients with schizophrenia initiated on risperidone long-acting therapy: the SOURCE study results. BMC Psychiatry 2011;11:167.

[49] Peluso MJ, Lewis SW, Barnes TR, Jones PB. Extrapyramidal motor side-effects of first- and second-generation antipsychotic drugs. Br J Psychiatry 2012;200 (5):387-92.

[50] Patel MX, Nikolaou V, David AS. Psychiatrists' attitudes to maintenance medication for patients with schizophrenia. Psychol Med 2003;33(1):83-9.

[51] Franz M, Ranger J, Hanewald B, Gallhofer B, Lay B. Influences on therapist's decisions for neuroleptic treatment in schizophrenia: the role of characteristics of the patient and the physician. Pharmacopsychiatry 2012;45 (7):261-8

[52] Leucht S, Heres S. Epidemiology, clinical consequences, and psychosocial treatment of nonadherence in schizophrenia. J Clin Psychiatry 2006;67(Suppl. 5):3-8.
[53] Medina E, Salva J, Ampudia R, Maurino J, Larumbe J. Short-term clinical stability and lack of insight are associated with a negative attitude towards antipsychotic treatment at discharge in patients with schizophrenia and bipolar disorder. Patient Preference Adherence 2012;6:623-9.

[54] Rossi G, Frediani S, Rossi R, Rossi A. Long-acting antipsychotic drugs for the treatment of schizophrenia: use in daily practice from naturalistic observations. BMC Psychiatry 2012;12:122.

[55] Shi L, Ascher-Svanum H, Zhu B, Faries D, Montgomery W, Marder SR. Characteristics and use patterns of patients taking first-generation depot antipsychotics or oral antipsychotics for schizophrenia. Psychiatr Serv (Washington, DC) 2007;58(4):482-8.

[56] Svedberg B, Backenroth-Ohsako G, Lutzen K. On the path to recovery: patients' experiences of treatment with long-acting injections of antipsychotic medication. Int J Mental Health Nurs 2003;12(2):110-8.

[57] Citrome L. Patient perspectives in the development and use of long-acting antipsychotics in schizophrenia: focus on olanzapine long-acting injection. Patient Preference Adherence 2009;3:345-55.

[58] Bauer SM, Schanda H, Karakula H, Olajossy-Hilkesberger L, Rudaleviciene P, Okribelashvili N, et al. Culture and the prevalence of hallucinations in schizophrenia. Compr Psychiatry 2011;52(3):319-25.

[59] Versola-Russo JM. Cultural and demographic factors of schizophrenia. Int J Psychosoc Rehabil 2005;10(2):89.

[60] Verdoux H, Pambrun E, Tournier M, Bezin J, Pariente A. Antipsychotic longacting injections: a community-based study from 2007 to 2014 of prescribing trends and characteristics associated with initiation. Schizophr Res 2016;178 (1-3):58-63.

[61] Patel MX, De Zoysa N, Bernadt M, David A. Depot and oral antipsychotics: patient preferences and attitudes are not the same thing. J Psychopharmacol (Oxf Engl) 2009;23(7):789-96.

[62] Iyer S, Banks N, Roy MA, Tibbo P, Williams R, Manchanda R, et al. A qualitative study of experiences with and perceptions regarding long-acting injectable antipsychotics: part II-physician perspectives. Can J Psychiatry 2013;58(5) Suppl. (1):23S-9S. 